\title{
Effects of Curcumin on Growth and Liver- protection in Common Carp, Cyprinus carpio
}

\author{
Yuanyuan Zhang ${ }^{1 *}$, Liping Song ${ }^{1}$, Hui Guo ${ }^{2}$, Jun $\mathrm{Wu}^{1}$, Xiaoli Wang ${ }^{1}$ and \\ Fangbin Yao ${ }^{1}$ \\ ${ }^{1}$ Freshwater Fisheries Research Institute of Shandong Province, Jinan 250013, China \\ ${ }^{2}$ Qilu Children's Hospital of Shandong University, Jinan 250022, China
}

\begin{abstract}
A B S T R A C T
We evaluated the growth performance and the hepatoprotective and antioxidant effects of curcumin against carbon tetrachloride $\left(\mathrm{CCl}_{4}\right)$-induced liver injury in common carp Cyprinus carpio. A 10-week feeding trial was carried out. A basal feed was supplemented with 0 (control), 30, 60, 120 and $240 \mathrm{mg} / \mathrm{kg}$ curcumin to formulate five experimental feeds. At the end of the feeding trial, the growth performance was determined. Subsequently, $\mathrm{CCl}_{4}$ was used for the model experiment. The plasma and liver were collected for the test after $72 \mathrm{~h}$. Results showed that there was a significant $(P<0.05)$ increase in weight gain rate (WG) and a special growth rate (SGR) of fish fed feeds supplemented with 60 and $120 \mathrm{mg}$ curcumin $\mathrm{kg}^{-1}$. When fish were induced by $\mathrm{CCl}_{4}$ after $72 \mathrm{~h}$, fish fed the diet supplemented with $120 \mathrm{mg}$ (P5) curcumin $\mathrm{kg}^{-1} \mathrm{had}$ significantly $(P<0.05)$ lower plasma GOT, GPT activities and MDA content and higher plasma TP content and activities of liver SOD, GSH, GSH-Px and plasma T-AOC than those of P1 group. Curcumin (120 $\mathrm{mg} \mathrm{kg}^{-1}$ curcumin per feed) inhibited the damage of liver tissue structure caused by carbon tetrachloride and made liver tissue structure return to normal. Meanwhile, dietary curcumin supplementation could also increase the live Nrf2 mRNA level and Nrf2 protein level in the liver nucleus, and those of the P5 group were highest. Overall, the results indicated that appropriate dietary curcumin supplementation could enhance the growth (especially 60 and $120 \mathrm{mg} \mathrm{kg}^{-1}$ curcumin per feed) of common carp and effectively protect the liver against $\mathrm{CCl}_{4}$ induced injury (especially $120 \mathrm{mg} \mathrm{kg}^{-1}$ curcumin per feed) in fish.
\end{abstract}

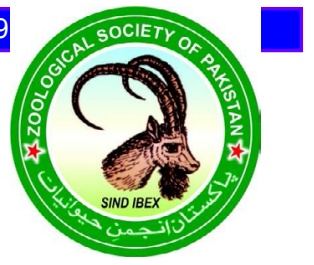

\section{INTRODUCTION}

$\mathrm{I}^{\mathrm{n}}$ n recent years, high-density aquaculture is on rapid development. However, there are also many problems such as antibiotic abuse, excess feeding, and nutrition imbalances, bacterial infections (Barton, 2002; Ming et al., 2012). These problems lead to the disorders of the metabolic system and liver damage, which lead to the large-scale outbreak of fish hepatobiliary syndrome (Hu et al., 2006). Therefore, it is urgent to understand the pathogenesis of fish hepatobiliary syndrome and take appropriate medicine in time.

Currently, antibiotics are used to treat the hepatobiliary syndrome. However, antibiotics often cause antibiotic resistance (Cabello, 2006). Besides, a large number of antibiotic residues in the body will cause the pathogen to develop a certain degree of drug resistance, and eventually to human health. Therefore, it is important to develop green and safe methods for the protection of liver damage in fish. Alternative environment-friendly approaches for the prevention and treatment of fish infectious diseases are highlighted in Chinese traditional herbal medicine as alternatives to antibiotic feed additives.

\footnotetext{
* Corresponding author: yyuanzhang2008@163.com 0030-9923/2021/0004-1211 \$ 9.00/0

Copyright 2021 Zoological Society of Pakistan
}

Curcumin is a natural yellow acidic phenol extracted from curcuma genus (Curcumalonga) plant such as turmeric (Curcuma longa) and acruginous turmeric rhizome (Rhizoma curcumae Aeruginosae) (Aggarwal et al., 2007). Recent studies have demonstrated a wide range of pharmacological effects of dietary curcumin, such as elimination of free radicals (Toda et al., 1985) and antioxidant (Ruby et al., 1995), relief of inflammation (Gupta et al., 2011), antibacterial effects, and immunomodulation. The transcription factor Nrf2 (nuclear factor crythroid 2-related factor 2) is a member of the basic leucine-zipper NF-E2 family and interacts with the antioxidant response element (ARE) in the promoter region of phase 2 detoxifying enzymes and finally improve the antioxidant capacity of fish by regulating the expression of a 2-phase enzyme. At present, studies on curcumin's anti-oxidation and protection against liver injury are mostly found in mice, Mus musculus (Ma et al., 2014; Han et al., 2009), livestock, and poultry (Zhang, 2015). The results of these studies indicated that curcumin had a protective effect on liver injury in mice, broilers (Gallus gallus), and other animals by activating Nrf2 activity (Jia et al., 2015). However, there are only few studies on this aspect of fish, only Yu et al. (2016) studied the protective effect of curcumin on the acute liver injury of grass carps, Ctenopharynodon idellus. 
$\mathrm{CCl}_{4}$ is a classical substance that can induce liver injury, which can damage the liver cell membrane and organelle membrane, resulting in lipid peroxidation of the membrane, and ultimately leading to liver function decline and liver cell necrosis (Adzet et al., 1987). It is widely used to construct liver injury models to screen liver protective drugs and study liver mechanism in mammals (Koneri et al., 2008). Similar to mammals, fish hepatocytes are also sensitive to $\mathrm{CCl}_{4}$ (Statham et al., 1978). $\mathrm{CCl}_{4}$ has been widely used to construct the liver injury model of fish in recent years (Koskinen et al., 2004). Given this, $\mathrm{CCl}_{4}$ was used as the classic toxicant to induce liver injury in common carp, Cyprinus carpio, in this study, and effects of dietary curcumin supplementation were studied on growth and liver-protection, to provide a theoretical basis for further development of liver protection drugs of fish.

\section{MATERIALS AND METHODS}

\section{Experimental feeds}

The formulation and proximate composition of the basal feed are shown in Table I. The basal feed consisted of $2 \mathrm{~mm}$ pelleted feed based on fish meal, soybean meal, fish oil, and soybean oil (protein $32.29 \%$, fat $7.57 \%$, and ash $8.17 \%$ ). The basal feed was supplemented with 0 (control), $30,60,120$, and $240 \mathrm{mg}$ curcumin $\mathrm{kg}^{-1}$. Curcumin (with purity $>99 \%$ ) was provided by Feida Chemical Reagent Company (Xi'an, China). For the preparation of experimental feeds, the ingredients were ground into fine powder through a 60 -mesh sieve. Feeds were prepared by mixing dry ingredients, and then oil and water were added $(40 \%, \mathrm{v} / \mathrm{w})$ to form a soft dough. The dough was then pelleted using a laboratory pellet machine and dried in a forced-air oven at room temperature. After drying, the feeds were broken into smaller pieces and sieved into proper pellet size. All feeds were stored at $-20^{\circ} \mathrm{C}$ until used.

\section{Experiment design}

The experiment was divided into six groups. Two control groups were fed with a basal feed for 10 weeks (the positive control, P1 and the negative control, P2), and four treatment groups were fed with feeds supplemented with $30,60,120$ and $240 \mathrm{mg}$ curcumin $\mathrm{kg}^{-1}$ for the entire 10week study duration (P3, P4, P5, and P6), respectively. At the end of the feeding period, groups P1, P3, P4, P5, and P6 were sampled to analyze the effect of dietary curcumin supplementation on the growth performance of carp. Subsequently, we conducted preliminary experiment based on the study of Du et al. (2013), and finally determined that the concentration of $\mathrm{CCl}_{4}$ solution $\left(\mathrm{CCl}_{4}\right.$ was diluted with olive oil) was $30 \%$. The $\mathrm{CCl}_{4}$ solution $(0.5 \mathrm{ml}$ per 100 g body weight) was injected into the abdominal cavity of P1, P3, P4, P5, and P6 groups. The P2 group was injected with olive oil in the same proportion. After $72 \mathrm{~h}$, samples were taken separately to investigate the effect of curcumin on the liver injury induced by $\mathrm{CCl}_{4}$ in fish. No feed was given to fish during the $\mathrm{CCl}_{4}$ challenge test.

Table I. Formulation and nutrient contents of the experimental diets.

\begin{tabular}{ll}
\hline Ingredients & Percentage dry weight $\mathbf{( \% )}$ \\
\hline Fish meal & 15 \\
Soybean meal & 40 \\
Beer yeast & 6 \\
Wheat middling & 28 \\
Soybean oil & 2.5 \\
Fish oil & 2.5 \\
Choline chloride (50\%) & 2 \\
Vitamin premix & a \\
Mineral premix & 1 \\
Calcium dihydrogen phosphate & 2 \\
Proximate composition (\%) & 1 \\
Crude protein & 32.29 \\
Ether extract & 7.57 \\
Ash & 8.17 \\
\hline
\end{tabular}

Note: ${ }^{a}$ Vitamin premix supplied the following vitamins (IU or $\mathrm{mg} /$ $\mathrm{kg}$ ): Vitamin A, 900000IU; Vitamin D,200000IU; Vitamin E, $4500 \mathrm{mg}$; Vitamin $\mathrm{K}_{3}, 220 \mathrm{mg}$; Vitamin $\mathrm{B}_{1}, 320 \mathrm{mg}$; Vitamin $\mathrm{B}_{2}, 1090 \mathrm{mg}$; Niacin, $2800 \mathrm{mg}$; Vitamin $\mathrm{B}_{5}, 2000 \mathrm{mg}$; Vitamin $\mathrm{B}_{6}, 500 \mathrm{mg}$; Vitamin $\mathrm{B}_{12}, 1.6$ $\mathrm{mg}$; Vitamin C, $5000 \mathrm{mg}$; Pantothenate, $1000 \mathrm{mg}$; Folic acid, $165 \mathrm{mg}$; Choline, $60000 \mathrm{mg}$. ${ }^{\mathrm{b}}$ Mineral premix supplied the following minerals $(\mathrm{g} / \mathrm{kg}): \mathrm{FeSO}_{4} \cdot 7 \mathrm{H}_{2} \mathrm{O}, 25 \mathrm{~g}$; $\mathrm{CuSO}_{4} \cdot 5 \mathrm{H}_{2} \mathrm{O}, 2.0 \mathrm{~g} ; \mathrm{ZnSO}_{4} \cdot 7 \mathrm{H}_{2} \mathrm{O}, 22 \mathrm{~g}$; $\mathrm{Na}_{2} \mathrm{SeO}_{3}, 0.04 \mathrm{~g} ; \mathrm{KI}, 0.026 \mathrm{~g} ; \mathrm{MnSO}_{4} \cdot 4 \mathrm{H}_{2} \mathrm{O}, 7 \mathrm{~g} ; \mathrm{CoCl}_{2} \cdot 6 \mathrm{H}_{2} \mathrm{O}, 0.1 \mathrm{~g}$.

\section{Fish husbandry}

Juvenile common carp were obtained from the fish farm of Freshwater Fisheries Research Institute of Shandong Province, where the experiment was also conducted. Before experiments, fish were fed with the basal feed for an acclimation period of 15 days. After acclimation, 540 fish (average weight, $6.35 \pm 0.022 \mathrm{~g}$ ) were randomly distributed into six groups across 18 circular fiberglass tanks ( $300 \mathrm{~L}$ ) with the density of 30 fish per tank. Fish were hand-fed with the experimental feeds three times $(08: 30,12: 30$, and 16:30) daily to apparent satiation for 10 weeks. A photoperiod was set at natural conditions. Water was maintained at $26 \pm 1.5^{\circ} \mathrm{C}, 6.8-7.0$ $\mathrm{pH}, \geq 6 \mathrm{mg}$ dissolved oxygen $\mathrm{L}^{-1}$, and $0.08-0.09 \mathrm{mg} \mathrm{NH}_{3}-\mathrm{N}$ $\mathrm{L}^{-1}$ over the experimental period. The flow rate of water in each tank was maintained at approximately $2 \mathrm{~L} \mathrm{~min}^{-1}$. 


\section{Sample collection}

At the end of the feeding trial, fish were fasted 24 $\mathrm{h}$ and then anesthetized by $100 \mathrm{mg} \mathrm{L}^{-1} \mathrm{MS}-222$ (tricaine methanesulfonate, Sigma, USA). The total number and weight of fish in each tank were determined. Then, 3 fish per tank were randomly sampled and blood was collected by the caudal venipuncture using $1 \mathrm{ml}$ heparinized syringes. The blood was centrifuged $(3500 \times \mathrm{g}, 10 \mathrm{~min}$, $4^{\circ} \mathrm{C}$ ) to obtain plasma. Plasma was separated and stored at $-80^{\circ} \mathrm{C}$ until further analysis. At the end, liver was taken out of 3 fish and a small piece was fixed in Bouin's solution for histological examination. The rest was stored at $-80^{\circ} \mathrm{C}$ until molecular immunological and antioxidant index analysis.

\section{Plasma biochemical measurements}

Plasma glutamic oxalacetic transaminase (GOT) and glutamic pyruvic transaminase (GPT) activities, total protein (TP) content and total antioxidant capacity (T-AOC) were measured using the colorimetric methods of kits purchased from the Nanjing Jiancheng Bioengineering Institute of China.

\section{The antioxidant status in liver}

The liver samples were homogenized in ice-cold phosphate buffer (1:10 dilution) (phosphate buffer: 0.064 $\mathrm{M}, \mathrm{pH7.4)}$. The homogenate was centrifuged $(3000 \times g$, $10 \mathrm{~min}, 4^{\circ} \mathrm{C}$ ), and aliquots of the supernatant were used to measure the hepatic levels of superoxide dismutase (SOD), malondialdehyde (MDA), glutathione peroxidase (GPX), and glutathione (GSH). SOD activity was determined by its ability to inhibit superoxide anion generated by a xanthine and xanthine oxidase reaction system (Marklund and Marklund, 1974). MDA was measured using a barbituric acid method (Drape et al., 1993). GPX activity was detected according to the method described by Flohé and Günzler (1984). GSH content was measured using the Colorimetric method. SOD and GPX activity and MDA and GSH content were measured by commercial kits from Nanjing Jiancheng Bioengineering Institute, Nanjing, China.

\section{Histological examination}

The liver was excised from different fish groups and processed as described by Khan and Parvez (2015). A physiological saline solution $(0.75 \% \mathrm{NaCl})$ was used to rinse and clean the tissues. They were fixed in aqueous Bouin's solution (75 ml saturated picric acid, $25 \mathrm{ml}$ formaldehyde (37-40\%), and $5 \mathrm{ml}$ glacial acetic acid) for $48 \mathrm{~h}$. Subsequently, liver tissue was processed through a graded series of alcohols, cleared in xylene, and embedded in paraffin wax. Sections were cut at 4-6 $\mu \mathrm{m}$ thickness using an 820-Spencer rotatory microtome, stained with hematoxylin-eosin (dissolved in 70\% alcohol) (Humason, 1972) and were mounted in Canada balsam. Thin sections $(20 \mu \mathrm{m})$ were stained with hematoxylin-eosin and observed with an Olympus BX61 photo-microscope $(\times 1000)$.

\section{qPCR analysis}

The PCR primers were produced by Shanghai General Biotechnology, Co., Ltd, China. Total RNA of the liver in the experiment groups ( 9 samples per group) were extracted by RNAiso Plus (TaKaRa, Japan) and measured by Nanodrop 2000 (Thermo Fisher Scientific, USA). The OD 260/280 of total RNA is 1.8-2.0. Primer 5.0 was used to design primers for Nrf2 genes for qRT-PCR analysis based on the obtained fragments (Table II). The RNA in each sample was diluted to $500 \mathrm{ng} / \mathrm{ml}$, and the following quantitative analysis was carried out for $2 \mu \mathrm{g}$ of the total RNA with a Two Steps SYBR $®$ PrimeScript ${ }^{\circledR}$ Plus RTPCR Kit (TaKaRa, Dalian). The real-time quantitative PCR (RT-PCR) was performed in $20 \mu$ reaction volumes under the following thermal profile: 1 cycle at $95^{\circ} \mathrm{C}$ for 15 min; 40 amplification cycles at $95{ }^{\circ} \mathrm{C}$ for $10 \mathrm{~s}, 55^{\circ} \mathrm{C}$ for $30 \mathrm{~s}, 72^{\circ} \mathrm{C}$ for $31 \mathrm{~s}$ and conducted by ABI 7500 real-time PCR system, and the $2^{-\triangle \triangle \mathrm{CT}}$ method was used for analysis.

Table II. Primers for real time PCR analysis of Nrf2 genes.

\begin{tabular}{ll}
\hline Primers & Primer sequence(5'-3') \\
\hline Nrf2-F & 5'-TCATACTGGGATTGTTTGCG-3' \\
Nrf2-R & 5'-AGCCTCATGTTACAGGGTGC-3' \\
$\beta$-actin-F & 5'-GCTATGTGGCTCTTGACTTCGA-3' \\
$\beta$-actin-R & 5'-CCGTCAGGCAGCTCATAGCT-3' \\
\hline
\end{tabular}

$\mathrm{F}$, forward primer; $\mathrm{R}$, reverse primer.

\section{Protein extraction and western blot analysis}

Total protein was isolated from liver tissues with RIPA buffer containing $25 \mathrm{mM}$ Tris- $\mathrm{HCl}$ ( $\mathrm{pH} 8.0$ ), $150 \mathrm{mM} \mathrm{NaCl}$, $1 \mathrm{mM}$ EDTA, $0.5 \%$ NP-40, 0.5\% sodium deoxycholate and $1 \%$ SDS. Protein concetrations were determined using Pierce BCA Protein Assay Reagent (Pierce Biotechnology). Proteins was separated by 2-DE gels, transferred to PVDF membranes (Millipore, Billerica, MA, USA) using a TransBlot $^{\circledR}$ SD semi-dry Transfer Cell (Bio-Rad) for $60 \mathrm{~min}$ at $18 \mathrm{~V}$. The membranes were blocked with 5\% skimmed milk in PBS, $\mathrm{pH} 7.4$ for $2 \mathrm{~h}$ at room temperature. Following three washes at $\mathrm{pH} 7.4$ with TBST, the membranes were incubated overnight at $4^{\circ} \mathrm{C}$ with $\mathrm{Nrf} 2$ rabbit polyclonal antibody (since there is no commercial Nrf2 antibody for common carp, the primary antibody of $\mathrm{Nrf} 2$ we used was prepared by ourselves.) diluted 1:1000 in TBST. After 
three washes in TBST, the membranes were incubated with the horseradish-peroxidase- (HRP) conjugated goat anti-rabbit $\operatorname{IgG}$ (\#111-035, Jackson, 1:10000) at $25^{\circ} \mathrm{C}$ for $2 \mathrm{~h}$. Immunoblot experiments were conducted using the Clarity ${ }^{\mathrm{TM}}$ Western ECL substrate (Bio-Rad) in duplicate, no variation in the results was observed. The PDQuest ${ }^{\mathrm{TM}}$ 2-D Analysis Software (BioRad) was used for matching and analysis of the antigenic protein spots on the 2-DE gels. Results shown in the figures are representative results from three independent experiments.

\section{Statistical analysis}

All data are presented as means \pm S.E. (standard error of the mean). Data were logarithmically transformed before subjection to one-way analysis of variance (ANOVA) using SPSS 17.0. When the overall treatment effect was found to be significantly different. The Duncan multiple range tests was conducted to compare the means between the levels of curcumin treatment. The level of significant difference was set at $P<0.05$.

\section{RESULTS}

Growth performance

After 10 weeks feeding, curcumin supplementation significantly affected the growth of carp. Fish fed feeds supplemented with 60 (P4) and 120 (P5) mg curcumin $\mathrm{kg}^{-1}$ had significantly higher weight gain (WG) and specific growth rate $(\mathrm{SGR})(P<0.05)$ than that of fish fed feeds supplemented with 0 (P1), 30 (P3) and 240 (P6) $\mathrm{mg}$ curcumin $\mathrm{kg}^{-1}$ (Table III). No significant differences were observed in WG and SGR between P1, P3, and P6 treatments $(P>0.05)$. FCR of fish under P6 treatment was higher $(P<0.05)$ than other groups. There was no significant difference in the survival, viserosomatic index (VSI), hepatosomatic index (HIS), and condition factor (CF) between the treatment group and control group.

Table III. Growth performance of Cyprinus carpio fed diets containing different levels curcumin ${ }^{1}, n=9 ; \bar{x} \pm \mathrm{SE}$.

\begin{tabular}{llllll}
\hline Variables & P1 & P3 & P4 & P5 & P6 \\
\hline Initial body weight $(\mathrm{g})$ & $6.35 \pm 0.01$ & $6.32 \pm 0.02$ & $6.4 \pm 0.05$ & $6.33 \pm 0.02$ & $6.35 \pm 0.01$ \\
Final body weight $(\mathrm{g})$ & $18.75 \pm 1.14^{\mathrm{a}}$ & $19.68 \pm 2.15^{\mathrm{a}}$ & $22.59 \pm 1.2^{\mathrm{b}}$ & $21.86 \pm 1.08^{\mathrm{b}}$ & $19.57 \pm 1.3^{\mathrm{a}}$ \\
$\mathrm{WG}^{2}(\%)$ & $195.28 \pm 9.38^{\mathrm{a}}$ & $211.39 \pm 8.1^{\mathrm{ab}}$ & $252.97 \pm 11.11^{\mathrm{b}}$ & $245.34 \pm 21.08^{\mathrm{b}}$ & $208.19 \pm 14.25^{\mathrm{ab}}$ \\
$\mathrm{SGR}^{3}\left(\% \mathrm{~d}^{-1}\right)$ & $2.12 \pm 0.02^{\mathrm{a}}$ & $2.23 \pm 0.03^{\mathrm{a}}$ & $2.74 \pm 0.08^{\mathrm{b}}$ & $2.70 \pm 0.12^{\mathrm{b}}$ & $2.31 \pm 0.05^{\mathrm{ab}}$ \\
$\mathrm{FCR}^{4}$ & $1.23 \pm 0.06^{\mathrm{a}}$ & $1.22 \pm 0.12^{\mathrm{a}}$ & $1.22 \pm 0.04^{\mathrm{a}}$ & $1.25 \pm 0.09^{\mathrm{a}}$ & $1.37 \pm 0.07^{\mathrm{b}}$ \\
Survival rate & $\%)$ & 100 & 100 & 97 & 100 \\
$\operatorname{VSI}^{6}(\%)$ & $10.45 \pm 0.45$ & $10.38 \pm 0.19$ & $10.95 \pm 0.77$ & $11.26 \pm 0.23$ & $10.89 \pm 0.51$ \\
$\mathrm{HIS}^{7}(\%)$ & $1.44 \pm 0.13$ & $1.39 \pm 0.35$ & $1.48 \pm 0.16$ & $1.19 \pm 0.11$ & $1.07 \pm 0.22$ \\
$\mathrm{CF}^{8}(\%)$ & $3.93 \pm 0.19$ & $3.81 \pm 0.26$ & $3.74 \pm 0.17$ & $3.56 \pm 0.21$ & $3.63 \pm 0.17$ \\
\hline
\end{tabular}

${ }^{1}$ Values are means \pm S.E. of three replications, values with different superscript letters in the same line are significantly different in the Duncan multiple range test $(P<0.05) ;{ }^{2}$ Weight gain $(\mathrm{WG})=($ Final body weight-initial body weight $) \times 100 /$ initial body weight; ${ }^{3}$ Specific growth rate $(\mathrm{SGR})=(\mathrm{LnWt}-$ $\left.\mathrm{LnW}_{0}\right) \times 100 / \mathrm{T}$, where $\mathrm{W}_{0}$ and $\mathrm{Wt}$ are the initial and final body weights, and $\mathrm{T}$ is the culture period in days; ${ }^{4} \mathrm{Feed}$ conversion ratio $(\mathrm{FCR})=$ total diet fed $(\mathrm{g}) /$ total wet weight gain $(\mathrm{g}) ;{ }^{5}$ Survival rate $=($ initial fish number-final fish number $) \times 100 /$ initial fish number; ${ }^{6}$ Viserosomatic index $($ VSI $)=$ Visceral weight $\times 100$ / final body weight; ${ }^{7}$ Hepatosomatic index $(\mathrm{HIS})=$ Liver weight $\times 100$ / final body weight; ${ }^{8}$ Condition factor $(\mathrm{CF})=$ Final body weight $\times 100 /$ $\mathrm{L}^{3}$, where $\mathrm{L}$ is length of fish body.

P1, positive control; P30, 30 mg curcumin $\mathrm{Kg}^{-1}$; P4, 60 mg curcumin $\mathrm{Kg}^{-1}$; $\mathrm{P}$, $120 \mathrm{mg}$ curcumin $\mathrm{Kg}^{-1} ; 240 \mathrm{mg}$ curcumin $\mathrm{Kg}^{-1}$.

Table IV. Effects of dietary curcumin supplementation on the plasma physiological indices of Cyprinus carpio before $\mathrm{CCl}_{4}$-challenge. $n=9 ; \bar{x} \pm \mathrm{SE}$.

\begin{tabular}{|c|c|c|c|c|c|c|}
\hline Variables & P1 & $\mathbf{P 2}$ & P3 & P4 & P5 & P6 \\
\hline GPT (U/L) & $24.58 \pm 2.22$ & $23.61 \pm 2.21$ & $21.87 \pm 3.15$ & $20.25 \pm 2.81$ & $18.54 \pm 3.66$ & $22.98 \pm 3.71$ \\
\hline GOT (U/L) & $26.86 \pm 6.17$ & $24.7 \pm 5.16$ & $25.25 \pm 5.79$ & $22.34 \pm 6.15$ & $20.52 \pm 5.76$ & $24.62 \pm 7.39$ \\
\hline $\mathrm{TP}(\mathrm{g} / \mathrm{L})$ & $22.79 \pm 2.69^{\mathrm{a}}$ & $21.56 \pm 1.58^{\mathrm{a}}$ & $28.67 \pm 2.47^{\mathrm{ab}}$ & $31.59 \pm 1.21^{\mathrm{b}}$ & $32.61 \pm 2.17^{\mathrm{b}}$ & $28.31 \pm 2.69^{\mathrm{ab}}$ \\
\hline T-AOC (U/mL) & $7.59 \pm 0.87^{\mathrm{a}}$ & $7.87 \pm 0.58^{\mathrm{a}}$ & $9.16 \pm 1.11^{\mathrm{b}}$ & $9.91 \pm 0.67^{\mathrm{bc}}$ & $10.27 \pm 1.09^{\mathrm{c}}$ & $8.92 \pm 1.02^{\mathrm{ab}}$ \\
\hline
\end{tabular}

Note: Means in the same line with different superscripts are significantly different $(P<0.05)$.

For details of groups, see Table III. 


\section{Plasma physiological index}

Table IV shows no significant difference in plasma GOT and GPT activities of fish between treatment groups when the fish was not treated with $\mathrm{CCl}_{4}(P>0.05)$, but the activity of GOT and GPT of fish fed feeds supplemented with curcumin were higher than that of the control group. The highest GPT and GOT activities were observed in P5 and P4 treatments, respectively. Although plasma TP content of fish under P4 and P5 treatments was significantly $(P<0.05)$ higher than that of the control group, no significant difference was observed in plasma TP of P3 and P6 treatment group compared with the control group. Fish under P3, P4 and P5 treatment group had significantly higher $(P<0.05)$ plasma T-AOC than fish in the control group, and T-AOC in the P5 treatment group was significantly higher than that of the P3 treatment group, but not significantly different from that of the P4 treatment group. There was no significant difference in T-AOC between the P6 group and the control group.

Table V showed that dietary curcumin supplementation significantly affected the activities of GOT and GPT, TP content, and T-AOC of fish plasma after $72 \mathrm{~h} \mathrm{CCl}_{4}-$ challenge $(P<0.05)$. Results indicated that fish in the P1 group had significantly $(P<0.05)$ higher GPT and GOT activities than fish in the P2 group. GPT activity of fish fed curcumin was not significantly different from that of fish in the P2 group, and the lowest GPT activity was observed in P5 treatment among curcumin treatments. GOT activities of fish under P4, P5, and P6 treatments significantly $(P<0.05)$ decreased compared with the $\mathrm{P} 1$ group. Among these three groups, the activity of GOT in the $\mathrm{P} 5$ group was lowest, and there was not significant different compared to the $\mathrm{P} 2$ group. The plasma TP content and T-AOC of fish in the $\mathrm{P} 1$ group were significantly $(P<0.05)$ lower than those of the P2 group. Plasma TP content and T-AOC increased firstly and then decreased from $\mathrm{P} 3$ to $\mathrm{P} 6$ groups, and the TP content and T-AOC of fish under P5 treatment were the peak value among these four groups and closest to those of $\mathrm{P} 2$ group.

\section{Liver antioxidant status}

Figure 1 shows that liver SOD activity and MDA content were significantly affected by dietary curcumin supplementation. Fish fed feeds supplemented with 60 and $120 \mathrm{mg}$ curcumin $\mathrm{kg}^{-1}$ had significantly $(P<0.05)$ higher SOD activity than that of the control group and P6 treatment group when the fish was not induced by $\mathrm{CCl}_{4}$. There was no significant difference in SOD activity between other treatment groups and the control group. After $72 \mathrm{~h} \mathrm{CCl}_{4}$-challenge, the SOD activity of the P1 and
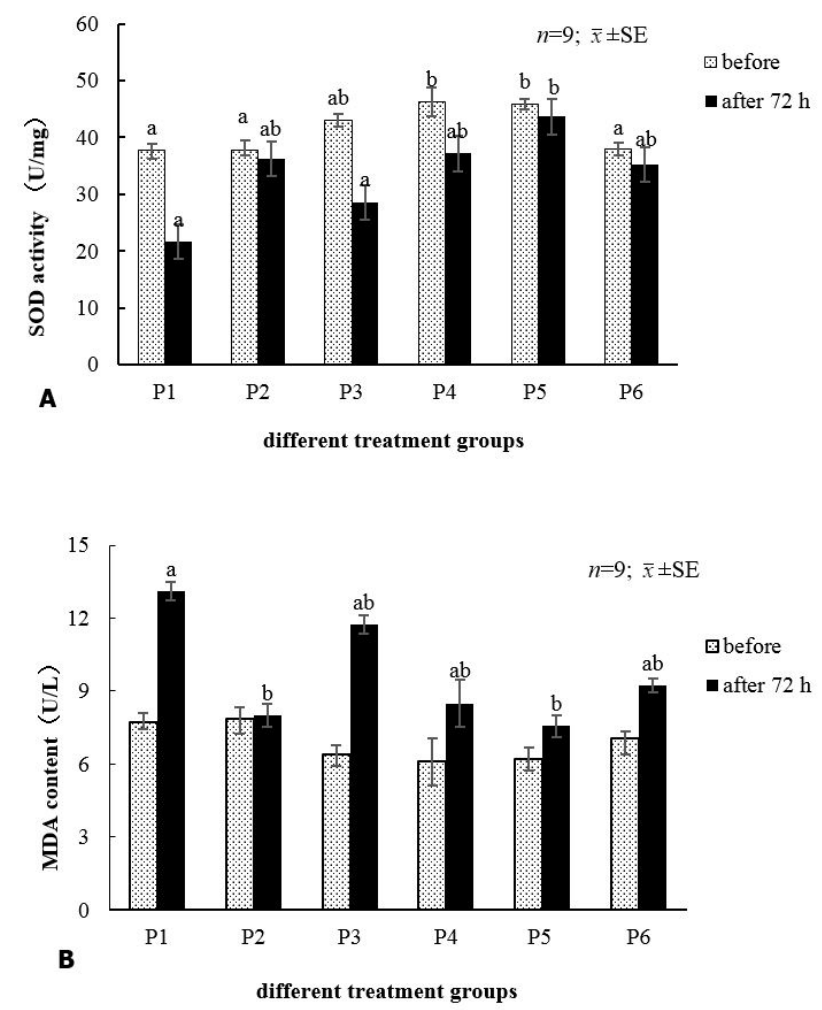

Fig. 1. Effects of curcumin on the activity of SOD (A) and MDA content (B) in $\mathrm{CCl}_{4}$-challenged Cyprinus carpio liver homogenate supernatant. For details of groups, see Table III.

Table V. Effects of dietary curcumin supplementation on the plasma physiological indexes of Cyprinus carpio after $72 \mathrm{~h} \mathrm{CCl}$-challenged. $n=9 ; \bar{x} \pm \mathrm{SE}$.

\begin{tabular}{|c|c|c|c|c|c|c|}
\hline Variables & P1 & $\mathbf{P 2}$ & P3 & P4 & P5 & P6 \\
\hline GPT (U/L) & $39.68 \pm 4.32^{\mathrm{a}}$ & $18.87 \pm 1.49^{b}$ & $30.78 \pm 3.65^{\mathrm{ab}}$ & $25.26 \pm 3.54^{\mathrm{ab}}$ & $23.45 \pm 1.57^{b}$ & $27.72 \pm 3.23^{\mathrm{ab}}$ \\
\hline GOT (U/L) & $53.42 \pm 11.54^{\mathrm{a}}$ & $23.48 \pm 5.46^{\mathrm{c}}$ & $40.67 \pm 5.2^{\mathrm{ab}}$ & $33.69 \pm 3.92^{\mathrm{b}}$ & $27.74 \pm 6.79^{\mathrm{bc}}$ & $33.66 \pm 9.6^{b}$ \\
\hline $\mathrm{TP}(\mathrm{g} / \mathrm{L})$ & $15.67 \pm 2.11^{\mathrm{a}}$ & $23.69 \pm 1.36^{\mathrm{b}}$ & $16.35 \pm 2.87^{\mathrm{a}}$ & $19.87 \pm 3.77^{\mathrm{ab}}$ & $22.09 \pm 3.82^{\mathrm{b}}$ & $18.89 \pm 3.05^{\mathrm{ab}}$ \\
\hline T-AOC (U/mL) & $3.77 \pm 0.34^{\mathrm{a}}$ & $7.25 \pm 0.86^{\mathrm{bc}}$ & $5.58 \pm 0.81^{\mathrm{b}}$ & $8.38 \pm 1.32^{\mathrm{c}}$ & $8.96 \pm 1.14^{\mathrm{c}}$ & $7.59 \pm 0.78^{\mathrm{bc}}$ \\
\hline
\end{tabular}

Note: Means in the same line with different superscripts are significantly different $(P<0.05)$. For details of groups, see Table III. 
P3 groups was lower compared to the P2 group. SOD activity increased firstly and then decreased as dietary curcumin from 30 to $240 \mathrm{mg} \mathrm{kg}^{-1}$. SOD activity of fish under the $\mathrm{P} 5$ group was significantly $(P<0.05)$ higher than that of P1 and P3 groups (Fig. 1A). On the contrary, MDA content decreased firstly and then increased with increasing curcumin from 30 to $240 \mathrm{mg} \mathrm{kg}^{-1}$. And fish fed $120 \mathrm{mg} \mathrm{kg}^{-1}$ curcumin had significantly $(P<0.05)$ low MDA content than fish under the P1group.

Figure 2 showed that dietary curcumin supplementation can improve GPX activity and GSH content of fish. Although GPX activity and GSH content in the P1 group was lower compared with the negative control group (P2) after $72 \mathrm{~h} \mathrm{CCl}_{4}$-challenge, these two indices increased firstly and then decreased with increasing dietary curcumin supplementation. The liver GPX activity and GSH content of fish under the P5 treatment group were significantly $(P<0.05)$ higher than those in the negative control group.
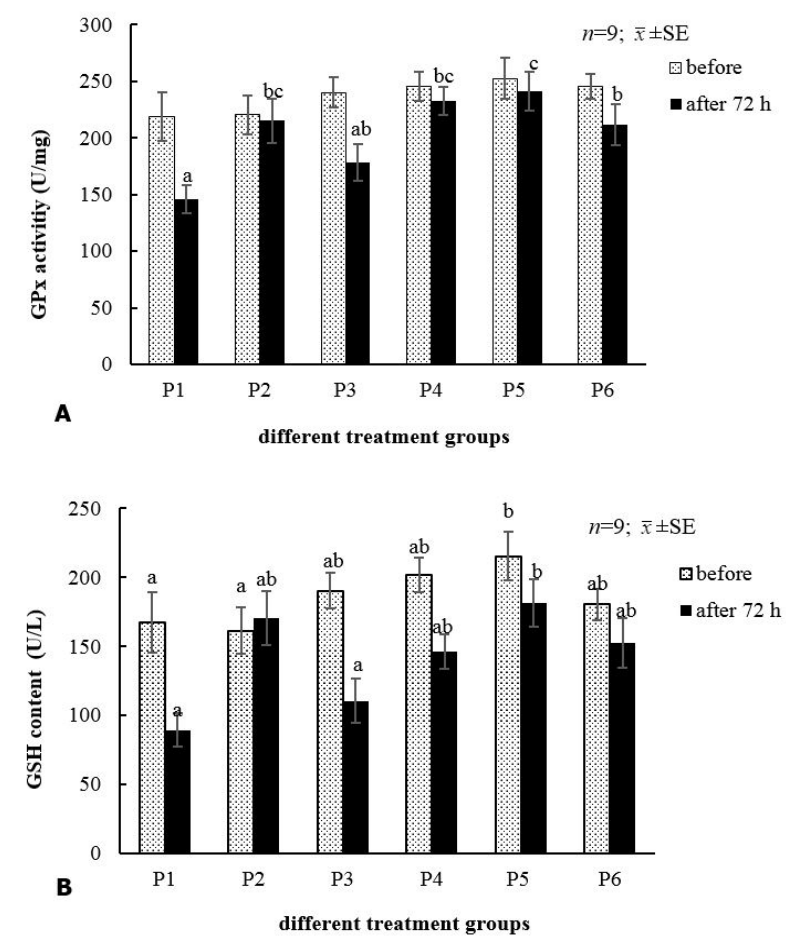

Fig. 2. Effects of curcumin on the activity of GPx (A) and GSH content (B) in $\mathrm{CCl}_{4}$-challenged Cyprinus carpio liver homogenate supernatant. For details of groups, see Table III.

\section{Liver histology}

Figure 3 shows no histopathological changes in the liver of P2 group fish. In P1, P3, P4, and P6 groups, there are varying degrees of nuclear hypertrophy, karyolysis, nuclear aggregation, and liver vacuolar degeneration after $72 \mathrm{~h} \mathrm{CCl}_{4}$ - challenge. While only mild liver vacuolar degeneration was observed in the $\mathrm{P} 5$ group.
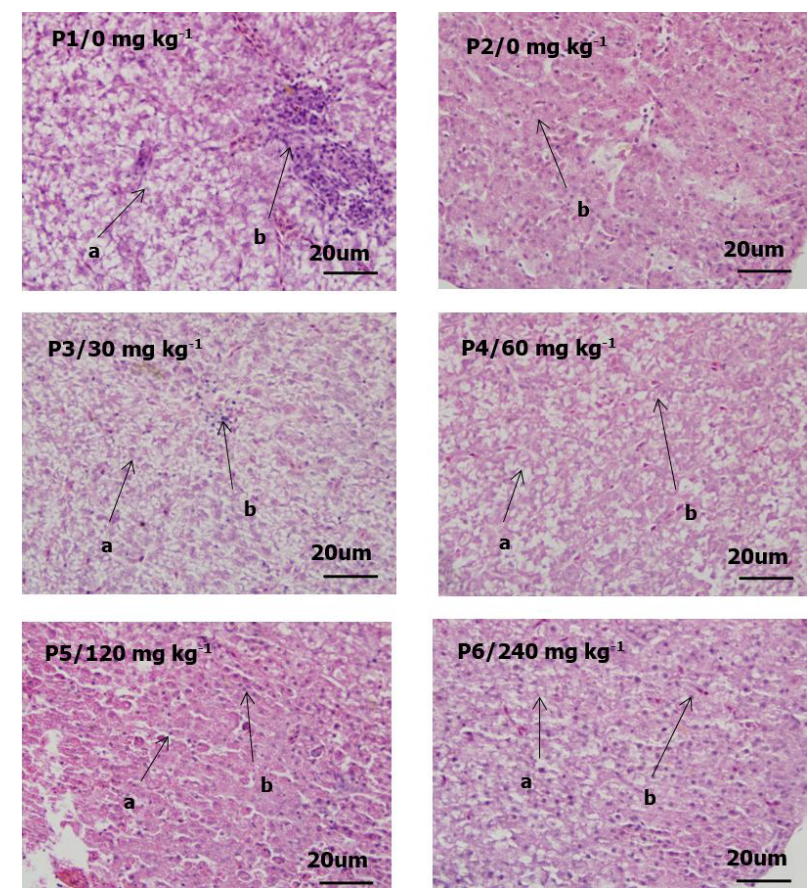

Fig. 3. Effects of curcumin on liver histology in Cyprinus carpio after $72 \mathrm{~h}$ of $\mathrm{CCl}_{4}$-challenged $(\times 1000)$.

$\mathrm{a}$, indicated adipose hollow space; $\mathrm{b}$, indicated cell nucleus.

\section{$q P C R$ and western blot analysis}

Figure 4 shows that dietary curcumin supplementation increased the liver Nrf2 mRNA level. Fish fed feed supplemented with 120 (P5) mg curcumin $\mathrm{kg}^{-1}$ had significantly $(P<0.05)$ higher liver Nrf2 mRNA level than fish fed feeds supplemented with 0 and $30 \mathrm{mg}$ curcumin $\mathrm{kg}^{-1}$, and there was no significant difference on the liver Nrf2 mRNA level among the other treatment groups. Although the liver Nrf2 mRNA level of fish in P1 and P3 groups decreased compared with the $\mathrm{P} 2$ group after $72 \mathrm{~h}$ $\mathrm{CCl}_{4}$-challenge, the Nrf2 mRNA level increased firstly and then decreased from the P1 to P6 group except for the P2 group. And the Nrf2 mRNA level in P4, P5, and P6 treatment groups was significantly higher than that of the P1 group. The highest Nrf2 expression was observed in the P5 treatment group.

Figure 5 shows that the Nrf2 protein level in the liver cell nucleus of common carp under curcumin treatment groups was higher than that of the control group. The Nrf2 protein level in the liver cell nucleus of different curcumin treatment groups was also different, and that of the P5 treatment group was highest. 


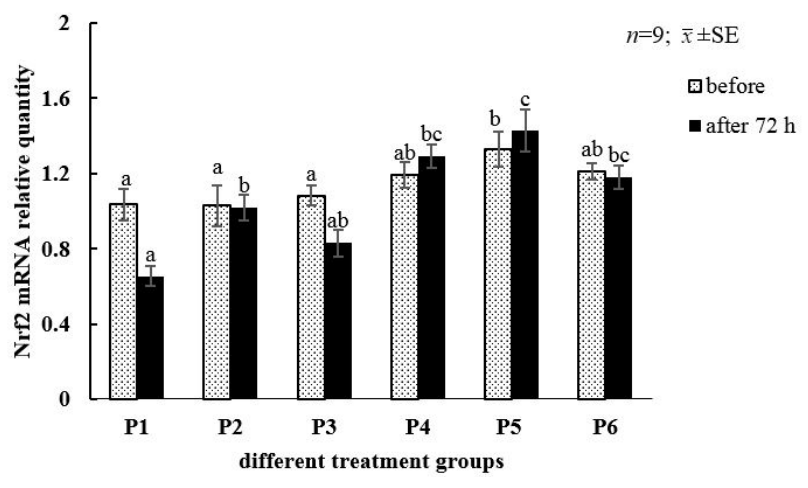

Fig. 4. Effects of curcumin on the liver Nrf 2 mRNA level of Cyprinus carpio in $\mathrm{CCl}_{4}$-challenged. For details of groups, see Table III.

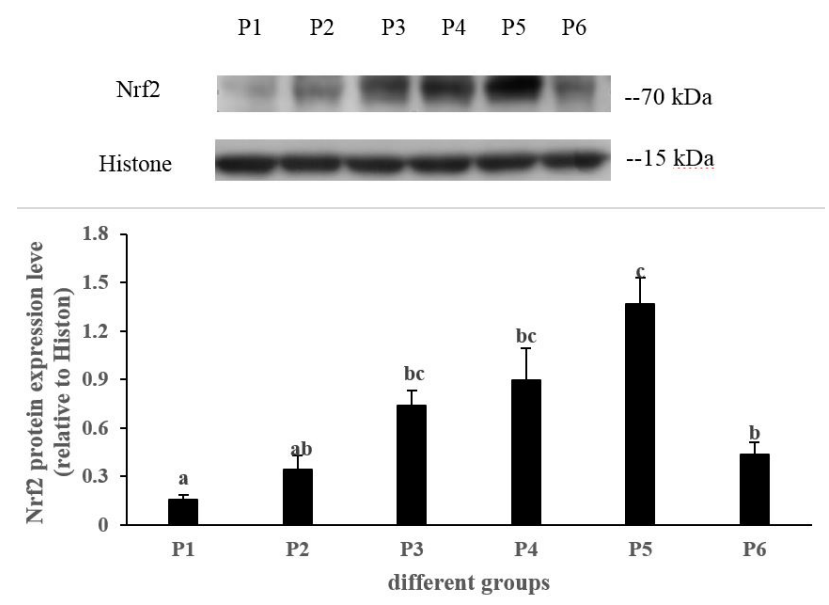

Fig. 5. Effects of curcumin on Nrf2 protein level in nucleus of Cyprinus carpio liver $72 \mathrm{~h}$ after $\mathrm{CCl}_{4}$-challenged. For details of groups, see Table III.

\section{DISCUSSION}

To improve growth and disease resistance of fish is most concerned. At present, antibiotics is widely used to promote growth and immunity in the breeding of land animals, which caused the pathogen to develop a certain degree of drug resistance, and eventually endanger human health. Therefore, alternative environment-friendly approaches for the prevention and treatment of fish diseases are highlighted. Chinese herbal medicine has received much attention as a potential alternative to antibiotics to prevent disease in aquaculture. Previous studies have shown that curcumin can promote gastrointestinal motility (Luo, 2012) and enhance the activity of digestive enzymes in the gut and pancreas of rats (Rattus norvegicus) (Platel and Srinivansan, 1996). It has also been reported that curcumin increased the activity of protease and diastase in the intestinal tract and improve the growth performance of tilapia (Cui et al., 2013). In the present study, diet supplemented with 60 and $120 \mathrm{mg}$ curcumin $\mathrm{kg}^{-1}$ for ten weeks significantly increased the WG and SGR of juvenile Cyprinus carpio, which is similar to the results of previous studies. One reasonable explanation for this result was that curcumin supplementation enhanced the immune response of fish, which increased growth performance (Zhang et al., 2014). However, fish fed the diet supplemented with 240 mg curcumin $\mathrm{kg}^{-1}$ had significantly lowered WGR and SGR and increased FCR than fish fed the diet supplemented with 60 and $120 \mathrm{mg}$ curcumin $\mathrm{kg}^{-1}$. It could be overdose of curcumin which caused an imbalance of intestinal flora, disturbed intestinal digestion and absorption (Liu et al., 2012). These results indicated that the growth performance of Cyprinus carpio was improved because of the diet supplemented with 60 and $120 \mathrm{mg}$ curcumin $\mathrm{kg}^{-1}$.

Increased level of plasma GOT and GPT are commonly recognized as indicator of liver damage (Sheikhzadeh et al., 2012; Hemre et al., 1996). In the present study, lower activities of GOT and GPT were observed in fish fed feeds supplemented with curcumin when compared to control, but the differences were not significant. This phenomenon indicated that the supplementation of curcumin did not cause any liver damage. When the fish were injected with $\mathrm{CCl}_{4}$ for $72 \mathrm{~h}$, plasma GOT and GPT activities of the P1 group significantly increased compared with the $\mathrm{P} 2$ group, indicating that $\mathrm{CCl}_{4}$ caused liver damage in Cyprinus carpio. However, fish fed the diet supplemented with 120 (P5) $\mathrm{mg}$ curcumin $\mathrm{kg}^{-1}$ had significantly lower GPT activity than fish in the P1 group, and the activity of GOT in fish under P4, P5, and P6 treatment groups was significantly lower than that of the $\mathrm{P} 1$ group. This result showed that supplementing the diet with a certain amount of curcumin had a liver protective effect in carp.

The TP content in the plasma is an important index to reflect the body's nutrition and metabolism status, and also indirectly reflects the body's antioxidant ability. Protein metabolism is heavily based on the liver, and when the liver is damaged, the plasma TP content will decrease. Therefore, TP can also be used as an indicator to detect liver function for clinical identification (Luo, 2012). Liu et al. (2009) think that Chinese herbal medicine can not only improve the antioxidant function of Acipenser schrenckii, but also significantly increase the plasma TP content, which was consistent with our result. Fish in P4 and P5 groups had significantly higher plasma TP content than control. However, after $72 \mathrm{~h} \mathrm{CCl}$-challenge plasma TP content of P1 group was significantly lower than that of P2 group, and plasma TP content tended to increase at first and then decrease with increasing curcumin supplementation. It shows that diet supplemented with a certain amount of 
curcumin could promote protein synthesis and protect the liver. This result could be attributed to curcumin's immune activation function, which could resist the damage of diseases, promote growth performance and protein metabolism of fish.

The metabolism of chemical substances in the liver mainly depends on phase 1 metabolism (such as GSH) and phase 2 enzyme metabolism (such as GPX, SOD). Increasing evidence suggests that the Keap1-Nrf2 complex is a key molecular target of chemopreventive phase 2 enzyme inducers (Kwak et al., 2004). As a cytoplasmic actin-binding protein, Keap1 is an inhibitor of Nrf2 that sequesters it in the cytoplasm under normal physiological conditions. However, inducers promote the release of Nrf2 from a cytoplasmic inhibitor Keap1 by altering the structural conformation of Keap1. The transcription factor Nrf2 is a member of the basic leucine-zipper NF-E2 family and interacts with the antioxidant response element (ARE) in the promoter region of phase 2 detoxifying enzymes (Kwak et al., 2004). Finally, the antioxidant capacity of the body is improved by regulating the expression of a 2-phase enzyme.

The present study indicates that orally administered curcumin at an appropriate dose (60 and $120 \mathrm{mg} \mathrm{kg}^{-1}$ ) significantly increased plasma antioxidant status in the carp, which might be related with the increase of SOD, GPX activities, GSH content, and decrease of MDA content. Consistent with our results, the previous studies have shown that curcumin could improve antioxidant capacity of Penaeus monodon by regulating antioxidant enzyme activities (Malar and Charles, 2013). After $72 \mathrm{~h} \mathrm{CCl}_{4}^{-}$ challenged, the liver Nrf2 mRNA level, SOD and GPX activity, GSH content of $\mathrm{P} 1$ group were significantly lower, MDA is significantly higher compared with P2 group. However, dietary curcumin (120 mg kg-1) significantly increased the activity of SOD and GPX , GSH content, decreased MDA content. Meanwhile, the Nrf2 protein level in the nucleus of Cyprinus carpio liver tended to increase at first and then to decrease with increasing curcumin supplementation. And the highest Nrf2 protein level in the nucleus was observed in the P5 group. However, the Nrf2 protein level in the high-dose group was significantly lower than that in the P5 group. One reasonable explanation was that high doses of curcumin might damage the structure of hepatocytes, thereby inhibiting Nrf2 metastasis (Sandur et $a l .$, 2007). Moreover, curcumin is a free radical scavenger and hydrogen donor, showing both antioxidant and prooxidant activities at high curcumin concentration, it is the later one, which predominates over the former (Banerjee et al., 2008). These results indicated that curcumin could increase the antioxidant status of the carp by promoting the release of Nrf2 from a cytoplasmic inhibitor Keap1, combining Nrf2 with the ARE in the promoter region of SOD and GPX and finally protecting carp liver.

Previous studies had confirmed that in liver vacuolar degeneration, necrosis and inflammatory cell infiltration were biological markers of liver injury (Bocci, 2006; León et al., 1998). However, the present study showed that dietary curcumin supplementation could reduce inflammatory cell infiltration and vacuolar degeneration of the liver, and in the P5 group. It means that curcumin (120 $\mathrm{mg} \mathrm{kg}^{-1}$ feed) could protect carp from liver injury induced by $\mathrm{CCl}_{4}$. Similar results were also observed in humans (Jing et al., 2002) and Mus musculus (Hemeida and Mohafez, 2008). This result directly verified the liverprotection function of curcumin in carp.

\section{CONCLUSION}

This study provides evidence that dietary supplementation with optimal curcumin (60 and $120 \mathrm{mg}$ $\mathrm{kg}^{-1}$ ) can increase the growth performance of Cyprinus carpio. Feed supplemented with $120 \mathrm{mg}$ curcumin $\mathrm{kg}^{-1}$ could increase the antioxidant status of carp by promoting the release of $\mathrm{Nrf} 2$, which increase the activity of antioxidant enzymes and finally protect carp from liver injury by $\mathrm{CCl}_{4}$. In this study, a liver-protection mechanism of curcumin in common carp is preliminary established, which provides theoretical guidance for the further development of liver protection drugs of fish.

\section{ACKNOWLEDGMENT}

This work was supported by Natural Science Foundation of Shandong Province (ZR2018PC030). The authors gratefully acknowledge the scientific research personnel's of the Fish Nutrition and Processing and Department, Freshwater Fisheries Research Institute of Shandong Province, Jinan City, PR China for their assistance during the sampling. We are also grateful to the management and workers of the fish farm of Freshwater Fisheries Research Institute of Shandong Province for all their assistance during the entire trial period.

\section{Statement of conflict of interest}

The authors have declared no conflict of interest.

\section{REFERENCES}

Adzet, T., Camarasa, J. and Laguna, J.C., 1987. Hepatoprotective activity of polyphenolic compounds from Cynara scolymus against $\mathrm{CCl}_{4}$ toxicity in isolated rat hepatocytes. J. Nat. Prod., 
50: 612-617. https://doi.org/10.1021/np50052a004 Aggarwal, B.B., Sundaram, C., Malani, N. and Ichikawa, H., 2007. Curcumin: The Indian solid gold. In: The molecular targets and therapeutic uses of curcumin in health and disease (eds. B.B. Aggarwal, Y-J Surh and S. Shishodia). Advances in Experimental Medicine and Blology, Springer, US. pp. 185-195. https://doi.org/10.1007/978-0-387-46401-5_1

Banerjee, A., Kunwar, A. and Mishra, B., 2008. Concentration dependent antioxidant/pro-oxidant activity of curcumin: Studies from AAPH induced hemolysis of RBCs. Chem. Biol. Interact., 174: 134-139. https://doi.org/10.1016/j.cbi.2008.05.009

Barton, B.A., 2002. Stress in fishes: A diversity of responses with particular reference to changes in circulating corticosteroids. Integr. Comp. Biol., 42: 517-525. https://doi.org/10.1093/icb/42.3.517

Bocci, V.A., 2006. Scientific and medical aspects of ozone therapy. State of the Art. Arch. Med. Res., 37: 425-435. https://doi.org/10.1016/j. arcmed.2005.08.006

Cabello, F.C., 2006. Heavy use of prophylactic antibiotics in aquaculture: A growing problem for human and animal health and for the environment. Environ. Microbiol., 8: 1137-1144. https://doi. org/10.1111/j.1462-2920.2006.01054.X

Cui, H.H., Liu, B., Ge, X.P., Xie, J., Xu, P., Miao, L.H., Sun, S.M., Liao, Y.J., Chen, R.L., Ren, M.C., Zhou, Q.L. and Pan, L.K., 2013. Effects of dietary curcumin on growth performance, biochemical parameters, HSP70 gene expression and resistance to Streptococcus iniae of juvenile gift tilapia, Oreochromis niloticus. Isr. J. Aquacul. Bamidgeh, 66: 986-996.

Drape, H.H., Squires, E.J., Mahmoodi, H., Wu, J., Agarwal, S. and Hadley, M., 1993. A comparative evaluation of thiobarbituric acid methods for the determination of malondialdehyde in biological materials. Free Radic. Biol. Med., 15: 353-363. https://doi.org/10.1016/0891-5849(93)90035-S

Du, J.L., Jia, R., Cao, L.P. and Yin, G.J., 2013. Protective effects of Polyporus umbellatus Polysaccharide on liver injury induced by carbon tetrachloride in Cyprinus carpio var. Jian. J. South. Agric., 44: 1564-1570 (in Chinese).

Flohé, L. and Günzler, W.A., 1984. Assay of glutathione peroxidase. Meth. Enzymol., 105: 115-121.

Gupta, S.C., Prasad, S., Kim, J.H., Patchva, S., Webb, L.J., Priyadarsini, I.K. and Aggarwal, B.B., 2011. Multitargeting by curcumin as revealed by molecular interaction studies. Nat. Prod. Rep., 28: 1937-1955. https://doi.org/10.1039/c1np00051a
Han, G., Wan, H., Zhai, G.Y. and Fang, Y., 2009. Protective effect of curcumin solid dispersionon acute liver injury induced by carbon tetrachloride in mice. Lishizhen Med. Mater. Med. Res., 20: 1321-1322.

Hemeida, R.A. and Mohafez, O.M., 2008. Curcumin attenuates methotraxate-induced hepatic oxidative damage in rats. J. Egypt. Nat. Cancer Inst., 20: 141-148.

Hemre, G.I., Waagbø, R., Hjeltnes, B. and Aksnes, A., 1996. Effect of gelatinized wheat and maize in diets for large Atlantic salmon (Salmo salar L.) on glycogen retention, plasma glucose and fish health. Aquacult. Nutr., 2: 33-39. https://doi. org/10.1111/j.1365-2095.1996.tb00005.x

$\mathrm{Hu}$, B.L., 2006. Research on the prevention of fish liver and gall syndrome. J. Aquacult., 27: 335.

Humason, G.L., 1972. Animal tissue techniques, $3^{\text {rd }}$ ed. WH Freeman and Company.

Jia, H.M., Wang, L.F. and Zhang, H.F., 2015. The study of Nrf2 related factor2 in protecting mouse from non-alcoholic steatohepatities. J. Inner Mongolia Agric. Univ. (Nat. Sci. edi.), 36: 14-17.

Jing, X., Ueki, N. and Cheng, J., 2002. Induction of apoptosis in hepatocellular carcinoma cell lines by emodin. Cancer Sci., 93: 874-882. https://doi. org/10.1111/j.1349-7006.2002.tb01332.x

Khan, M.H. and Parvez, S., 2015. Hesperidin ameliorates heavy metal induced toxicity mediated by oxidative stress in brain of Wistar rat. $J$. Trace Elem. Med. Biol., 31: 53-60. https://doi. org/10.1016/j.jtemb.2015.03.002

Koneri, R., Balaraman, R. and Firdous, K.M.V., 2008. Hepatoprotective effects of Momordica cymbalaria Fenzl. against carbon tetrachloride induced hepatic injury in rats. Pharmacology, 1: 365-374.

Koskinen, H., Pehkonen, P., Vehni I., E., Krasnov, A., Rexroad, C. and Afanasyev, S., 2004. Response of rainbow trout transcriptome to model chemical contaminants. Biochem. biophys. Res. Commun., 320: 745-753. https://doi.org/10.1016/j. bbrc.2004.06.024

Kwak, M.K., Wakabayashi, N. and Kensler T.W., 2004. Chemoprevention through the Keap1Nrf2 signaling pathway by phase 2 enzyme inducers. Mutat. Res. Fundam. Mol. Mech. Mutagen., 555: 133-148. https://doi.org/10.1016/j. mrfmmm.2004.06.041

León, O.S., Menéndez, S., Merino, N., Castillo, R., Sam, S. and Pérez, L., 1998. Ozone oxidative preconditioning: a protection against cellular damage by free radicals. Mediators Inflamm., 7: 
289-294. https://doi.org/10.1080/09629359890983

Liu, B., Xu, L., Ge, X., Xie, J., Xu, P., Zhou, Q., Pan, L. and Zhang, Y., 2013. Effects of mannan oligosaccharide on the physiological responses, HSP70 gene expression and disease resistance of Allogynogenetic crucian carp ( Carassius auratus gibelio ) under Aeromonas hydrophila infection. Fish Shellf. Immun., 34: 1395-1403. https://doi. org/10.1016/j.fsi.2013.02.028

Liu, H.B., Huang, J. and Ma, A.Z., 2009. Effects of the Chinese medicinal herb compound additives on growth and blood biochemical indicator of Amur sturgeon (Acipenser sch-rencki Brandt). Chinese J. Fish., 22: 14-18 (in Chinese).

Liu, W., Feng, Q., Li, Y., Ye, L., Hu, M. and Liu, Z.Q., 2012. Coupling of UDP-glucuronosyltransferases and multidrug resistance-associated proteins is responsible for the intestinal disposition and poor bioavailability of emodin. Toxicol. appl. Pharmacol., 265: 326-324. https://doi. org/10.1016/j.taap.2012.08.032

Luo, S., 2012. The study on mechanism of promoting gastrointestinal peristalsis in mice by curcumin. QingDao University (in Chinese).

Ma, X.L., Li, X.M., Chu, F., Pharmacy, S.O., University, A.M. and Pharmacy, D.O., 2014. Protective effect of curcumin on liver injury induced by endoplasmic reticulum stress in mice. Acta Univ. Med. Anhui, 49: 1629-1633.

Malar, H.L.V. and Charles, P.M., 2013. Effect of turmeric Curcuma longa Linn. extract on immunity and resistance to Vibrio harveyi in black tiger shrimp Penaeus monodon. Int. J. Res. Zool., 3: 21-26.

Marklund, S. and Marklund, G., 1974. Involvement of the superoxide anion radical in the autoxidation of pyrogallol and a convenient assay for superoxide dismutase. Eur. J. Biochem., 47: 469-474. https:// doi.org/10.1111/j.1432-1033.1974.tb03714.X

Ming, J.H., Xie, J., Xu, P., Ge, X.P., Liu, W.B. and Ye, J.Y., 2012. Effects of emodin and vitamin $\mathrm{C}$ on growth performance, biochemical parameters and two HSP70s mRNA expression of Wuchang bream (Megalobrama amblycephala Yih) under high temperature stress. Fish Shellf. Immunol., 32: 651661. https://doi.org/10.1016/j.fsi.2012.01.008

Platel, K. and Srinivansan, K., 1996. Influence of dietary spices or their active principles on digestive enzymes of small intestinal mucosa in rats. Int. J. Fd. Sci. Nutr., 47: 55-59. https://doi. org/10.3109/09637489609028561

Ruby, A.J., Kuttan, G., Babu, K.D., Raiasekharan, K.N. and Kuttan, R., 1995. Anti-tumor and antioxidant activity of natural curcuminoids. Cancer Lett., 94: 79-83. https://doi.org/10.1016/03043835(95)03827-J

Sandur, S.K., Ichikawa, H. and Pandey, M.K., 2007. Role of pro-oxidants and antioxidants in the anti-inflammatory and apoptotic effects of curcumin (diferuloylmethane). Free Radic. Biol. Med., 43: 568-580. https://doi.org/10.1016/j. freeradbiomed.2007.05.009

Sheikhzadeh, N., Tayefi-Nasrabadi, H., Oushani, A.K. and Enferadi, M.H.N., 2012. Effects of Haematococcus pluvialis supplementation on antioxidant system and metabolism in rainbow trout (Oncorhynchus mykiss). Fish Physiol. Biochem., 38: 413-419. https://doi.org/10.1007/s10695-0119519-7

Statham, C.N., Croft, W.A. and Lech, J.J., 1978. Uptake, distribution, and effects of carbon tetrachloride in rainbow trout (Salmo gairdneri). Toxicol. appl. Pharmacol., 45: 131-140. https://doi. org/10.1016/0041-008X(78)90034-0

Toda, S., Miyase, T., Arichi, H., Tanizawa, H. and Takino, Y., 1985. Natural antio-xidants. III. Antioxidant components isolated from rhizome of Curcuma longa L. Chem. Pharm. Bull., 33: 17251728. https://doi.org/10.1248/cpb.33.1725

Yu, Y.Z., Yu, S.M., Xiong, W.J., Zhang, S.Y. and Xu, Z.Q., 2016. The protective effect of curcumin in acute hepatic injuried Ctenopharyngodon idellus. Hubei Agric. Sci., 55: 1514-1517 (in Chinese).

Zhang, J.F., 2015. The protective effects of curcumin on mitochondrial oxidant damages in animals and the potential antioxidant mechanism. Graduation thesis, Nanjing Agriculture University (in Chinese).

Zhang, Y.Y., Liu, B., Xie, J., Ge, X.P., Liu, W.B., Ren, M.C., Zhou, Q.L. and Sun, S.M., 2014. Effects of dietary emodin supplementation on growth performance, non-specific immune responses, and disease resistance to Aeromonas hydrophila in juvenile Wuchang bream (Megalobrama amblycephala). Isr. J. Aquacult. Bamidgeh, 979: 16. 